\title{
Towards Automation in Admission Process as a Tool to Enhance Quality of Engineering Education at Tribhuvan University
}

\author{
Babu Ram Dawadi', Daya Sagar Baral ${ }^{2}$ \\ Department of Electronics and Computer Engineering, Pulchowk Campus, Tribhuvan University Nepal \\ Corresponding author(s): ['baburd, $\left.\left.{ }^{1} d s b a r a l\right] @ i o e . e d u . n p\right]$
}

Received: Feb 28, $2017 \quad$ Revised: April 20, $2017 \quad$ Accepted: April 27, 2017

\begin{abstract}
Institute of Engineering (IOE), Tribhuvan University (TU) is the government owned oldest institution in Nepal providing quality education in the engineering domain since 1972. However in the recent decade, other several universities are established in the country, IOE hasn't lost its popularity with its major features to have dedication on quality education to fulfill the world class education. As a public institution, it provides equal opportunities for all qualified citizens to enter into the university education. With the increasing number of affiliated colleges and applicants, the entrance exam and admission system are becoming challenging. Accepting the challenges, IOE adapted online applications and admit card generation with computer based entrance exam since 2014. Since recent past years, the student pass rate in the semester exams is not satisfactory. It raised the quality issues and required to find the causes so as to enhance quality. However there are several factors that affect the education quality, we identified that the admission process followed in most of the affiliated colleges is partially in the meritorious basis that affects the semester exam results. From this paper, we analyzed the past admission process and the student's status in semester exam where we tried to co-relate the quality intake in entrance exam and the semester exam of IOE. We proposed an optimal technical framework to admit merit based applicants through online centralized admission system that helps to overcome the admission challenges and enhance the quality of engineering education of IOE.
\end{abstract}

Keywords: Central admission system, IOE, semester, quality, online, entrance

\section{Introduction}

Tribhuvan University, Institute of Engineering is the oldest technical institute in the country. It has been producing quality engineers in the different streams as per the industry requirements since its establishment. IOE has four constituent campuses and ten affiliated colleges. These days IOE has been offering bachelors, masters and Ph.D. programs in different engineering streams. IOE always take entrance exam among the highly competent students throughout the country providing equal opportunity for applicants for the entry in its bachelor's and master's program. The Entrance Exam is proved itself as one of the outstanding example of fair exam system in Nepal [7]. This entrance become the basis of quality intake and measured as the big contribution in the quality control of engineering education. 
With the growing demand on bachelor/masters of engineering program and the tremendous increase of applicants, IOE gradually increased the bachelor programs together with the total student intake in its campus/colleges. After BE was started in 1984, programs were gradually added on Electrical (1994), Electronics (1994), Mechanical (1995), Architecture (1995), Computer (1998), Agricultural (2000) and Geomatics (2012) Engineering. Master level programs were also gradually increased and till 2016, IOE offers M.Sc. in 21 streams. Some new streams like Aeronautical Engineering, Biomedical Engineering, Chemical Engineering in bachelor level and Bio-Informatics, Energy Efficient Buildings, Mechanical Design \& Engineering in masters' level are already in the pipeline to be offered [1]. IOE has decided to phase out the diploma program in 2012 and fully focused on the bachelor and master's program. Central campus Pulchowk also offers Ph.D. degree in all streams.

IOE has been conducting its entrance examination every year since 1972 with the major objective to select highly qualified students to its campuses/colleges. From the recent past four years records as seen on Fig. 1, there were more than 10,000 competitive applicants in the entrance exam of bachelors program. Hence less than $35 \%$ students were selected for the admission $[2,4]$.

As being the technical institute, historically IOE is always ahead in the use of technology. The increasing burden in the manual processing of the entrance exam enforces IOE to step into the automatic result processing system. Since 2004, IOE developed automatic answer sheet scanning and processing system and started online based application since 2009. From the year 2014, IOE has started fully computer based entrance examination at its resourceful centers at Pulchowk. The fully managed and hassle free application system of IOE entrance examination allows applicants to simply apply and receive admit card with specified time slot from online registration system.

Entrance exam is just an eligibility test of the applicants. IOE Entrance exam board publishes the result of entrance as eligible students. Then the eligible candidates themselves have to apply separately to campus/colleges based on their rank secured for admission. The separate applications and admission processing creates non-uniformity in the admission process. We found discrepancies in admission process over IOE campuses and colleges that causes trouble to candidates to properly identify the campus/colleges about where their rank is fit to admit. This sometimes creates situation like meritorious candidates not to get chance to admit to any campus/colleges. Along with this, there are several admission hurdles in the existing situation of admission process. We conceptualized this paper so as to avoid the existing trouble in the IOE admission process and present the framework for uniform, hurdle free fully online based admission system.

\section{Status Measure of Current BE Admission Process at IOE}

Continuous improvement in the academic environment and achieving excellence in producing quality engineers is the main motto of IOE. After automating the BE \& M.Sc. entrance system, IOE is proceeding towards the automation of admission process for all of its campuses/colleges where the research study carried out in $2016[5,6]$ thoroughly investigated the existing system and recommend reform in admission process of IOE. We, the member of that research team reviewed the study documents and propose the suitable administrative and technical framework for the automation of IOE admission system. Table I \& II shows the list of programs offered in constituent campuses and affiliated colleges of IOE with maximum admission capacity [3].

The major concern is that once the entrance result is published, majority of the eligible candidates don't have idea where they can admit based on their rank in the range 60 to $70 \%$ of their score. 
Hence candidates roamed around and frequently visit the campus/colleges in the admission process. The information about the admission are not well maintained and lack of transparency in the admission system compels students to visit many colleges and stay on long queue for the admission. It has been seen that fully merit based admission system has not been followed in the affiliated colleges. Following major issues are found in the existing admission system at IOE that is not supporting intake of the best meritorious candidates in most of the IOE campus/colleges.

- Non-uniform merit based admission system: Although the constituent campuses of IOE follow fully merit based admission process with the well scheduled time line, admission process of majority of the affiliated colleges is not fully merit based. Immediately after the publication of entrance result, most of the affiliated colleges invite the admission application and perform admission with rank range on the first come first serve basis. The absence of merit based system probably increase the chances of losing the candidates having upper position in merit list and finally affects the overall quality intake. This causes the intake of poor candidates that affects the quality of semester results.

- Partial automation system in the admission process: Although IOE Pulchowk campus has fully online based application processing and admission list generation and computerized admission system, other constituent campuses have partially online system in the admission process. Most of the constituent campuses receive the priority application form online and generate the admission list manually. Similarly few affiliated colleges have partially online based admission system. The manual processing frequently draw errors in the priority based admission list generation and lengthen the admission timeline and compel candidates visit the campus/colleges frequently.

- Non-uniform Admission Schedule: The admission schedule at IOE is quite lengthy. Generally entrance exam occurs in July/August while students shall be admitted till the first week of the beginning of class (mid of November). Every campus/college has their own admission committee and publishes their own admission schedule which is not uniform. There is no single information portal from where candidates see and apply. Candidates visit to different campus/colleges to apply and see the admission list. It is not sure whether their rank is sufficient to admit at one campus/college.

Table I: Programs and Enrollment Seats in Constituent Campuses

\begin{tabular}{|l|c|c|c|c|c|c|c|c|}
\hline \multirow{3}{*}{ Program } & \multicolumn{8}{|c|}{ Admission Targets of Constituent Campuses } \\
\cline { 2 - 10 } & Pulchowk Campus & \multicolumn{2}{c|}{$\begin{array}{c}\text { Paschimanchal } \\
\text { Campus }\end{array}$} & \multicolumn{2}{c|}{$\begin{array}{c}\text { Purwanchal } \\
\text { Campus }\end{array}$} & \multicolumn{2}{c|}{$\begin{array}{c}\text { Thapathali } \\
\text { Campus }\end{array}$} \\
\cline { 2 - 10 } & Regular & Full-Fee & $\begin{array}{c}\text { Regu- } \\
\text { lar }\end{array}$ & Full-Fee & Regular & $\begin{array}{c}\text { Full- } \\
\text { Fee }\end{array}$ & $\begin{array}{c}\text { Regu- } \\
\text { lar }\end{array}$ & $\begin{array}{c}\text { Full- } \\
\text { Fee }\end{array}$ \\
\hline Civil & 108 & 84 & 36 & 108 & 24 & 72 & 24 & 72 \\
\hline Architecture & 24 & 24 & - & - & 12 & 36 & 12 & 36 \\
\hline Electrical & 24 & 24 & 12 & 36 & 12 & 36 & - & - \\
\hline $\begin{array}{l}\text { Electronics \& } \\
\text { Communica- } \\
\text { tions }\end{array}$ & 24 & 24 & 12 & 36 & 12 & 36 & 12 & 36 \\
\hline Mechanical & 24 & 24 & 12 & 36 & 12 & 36 & - & - \\
\hline
\end{tabular}




\begin{tabular}{|l|c|c|c|c|c|c|c|c|}
\hline Computer & 24 & 24 & 12 & 36 & 12 & 36 & - & - \\
\hline Agriculture & - & - & - & - & 12 & 36 & - & - \\
\hline Industrial & - & - & - & - & - & - & 12 & 36 \\
\hline Geomatics & - & - & 12 & 36 & - & - & - & - \\
\hline Automobile & - & - & - & - & - & - & 12 & 36 \\
\hline Total & $\mathbf{2 2 8}$ & $\mathbf{2 0 4}$ & $\mathbf{9 6}$ & $\mathbf{2 8 8}$ & $\mathbf{9 6}$ & $\mathbf{2 8 8}$ & $\mathbf{7 2}$ & $\mathbf{2 1 6}$ \\
\hline \multicolumn{8}{|c|}{ Grand Total } \\
\hline
\end{tabular}

Table II: Programs and Enrollment Seats in Affiliated Colleges

\begin{tabular}{|c|c|c|c|c|c|c|c|c|c|c|}
\hline \multirow[b]{2}{*}{ Programs } & \multicolumn{10}{|c|}{ Admission Targets of Affiliated Colleges } \\
\hline & 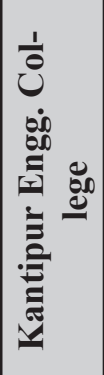 & 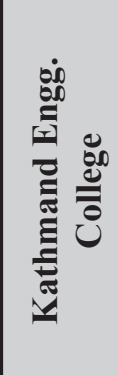 & 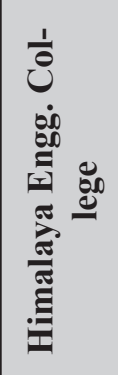 & 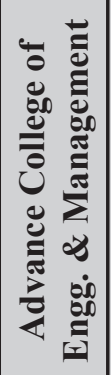 & 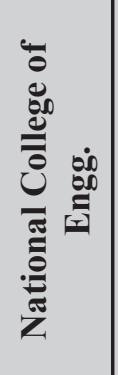 & 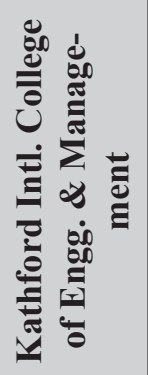 & 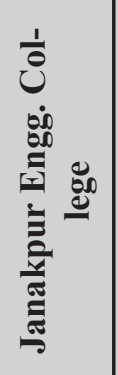 & 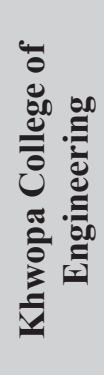 & 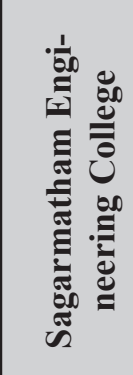 & 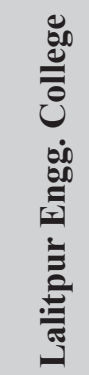 \\
\hline Civil & 88 & 121 & 96 & 120 & 96 & 80 & 96 & 96 & 48 & 48 \\
\hline Architecture & - & 55 & 24 & - & - & - & - & - & - & - \\
\hline Electrical & - & 44 & - & 40 & 40 & - & - & 48 & - & - \\
\hline $\begin{array}{l}\text { Electronics \& } \\
\text { Communica- } \\
\text { tion } \\
\end{array}$ & 88 & 132 & 48 & 88 & 53 & 48 & 48 & - & 48 & - \\
\hline Computer & 132 & 88 & 66 & 88 & 53 & 48 & 48 & - & - & - \\
\hline Total & \begin{tabular}{|l|}
308 \\
\end{tabular} & 440 & 234 & 336 & 250 & 176 & 192 & 144 & 96 & 48 \\
\hline \multicolumn{10}{|c|}{ Grand Total } & 2224 \\
\hline
\end{tabular}
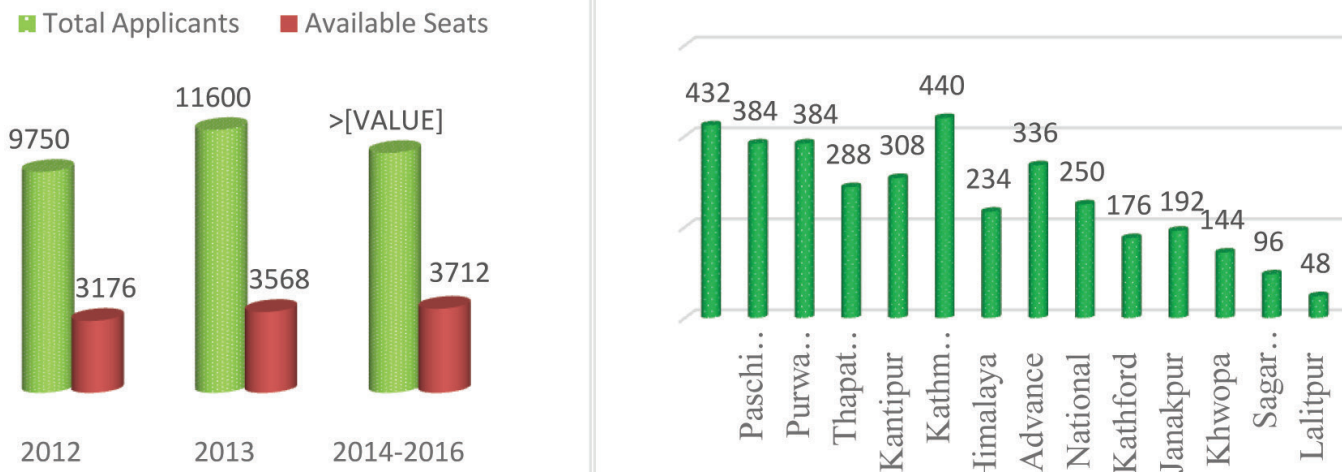

Fig. 1: Total Applicants \& Seats at IOE (left), Campus/College Total Available Seats (right) 
- Disturbances in admission process: The fact that we can't avoid the external interventions due to unstable political situation of Nepal, other seen and unseen strikes/bandhas during the admission period frequently disturbs the admission process and pollute the academic environment in campus/colleges.

- Candidate's interest mismatch with the available program: The demand on the subjects are frequently changing with the change of market whims/demands. Since the recent past few years, civil engineering and computer engineering streams are highly demandable while some years before, electronics engineering was highly demanding subject. The job in the market is driving the subject demands in university education of Nepal. Candidates who don't get subject of their choice has the chances either to choose other universities/ abroad or reappear the entrance examination next year making the target to admit on subject of his/her choice.

\section{Methodology}

We took almost $90 \%$ admitted students as sample to analyze the eligible candidates form entrance and their result in the semesters since the year 2069 (2012). IOE set the pass threshold every year in the entrance exam for the eligibility of candidate to admit into BE/BArch programs. For this analysis, a $5 \%$ interval of secured percentage in marks were taken like greater than $90 \%, 85$ to $90 \%, 80$ to $85 \%$ till 40 to $45 \%$. With this interval, the admitted students and their pass rates in the semester result in each program were analyzed. SPSS Clementine tool was used for data analysis while MS-Access and SQL were used for cross verification and validation of data obtained for this analysis.

\section{Co-Relation between Admitted Students and Their Semester Results}

Fig. 2, 3 and 4 shows the percentage of eligible students admitted in the corresponding year 2012, $2013 \& 2014$. This clearly shows that students who secure the entrance score in the range from 70 to $85 \%$ are admitted higher in percent. For over ten thousands candidates, six thousands were generally passed with IOE stated threshold in the entrance exam. Among this six thousands eligible candidates, IOE requires 3712 students as total admission in its campus/colleges. Looking from the rank, those candidates who secure around 50\% marks in the entrance exam are ranked around 3712. It means, if IOE strictly applies the merit based admission at its affiliated colleges, we should find very few candidates below 50\% admitted but the chart shows that lots of students in numbers between the range 40 to $50 \%$ were admitted. The major focus of IOE is to minimize the intake of the lowest eligible candidates with marks less than $50 \%$. It is seen that significant number of students having marks less than $50 \%$ admitted at IOE. It is expected that one of the factors that affects the low pass rate in semester result is the intake of low ranking students. Analyzing the semester results of those admitted students since 2012 verified the above expectation. The pass rate of low ranking students is very low as compared with the pass rate of higher ranking students in the entrance exam. We analyzed the regular and back exam of year 2012, 2013 and 2014 batch students. The result status was found to be almost same on all semester results like shown in the Fig. 5, 6 and 7 that depict the semester results status of admitted students with different entrance ranking. The semester exam pass rate on individual programs gradually decreased according to the entrance rank of the student, i.e., lower the rank lower is the pass rate. The total pass rate in the semester exam seems linearly decreasing form almost $90 \%$ to $12 \%$. Students having entrance score in the range $40 \%$ to $60 \%$ have almost 12 to $15 \%$ pass rates only. For the precise descriptions of the charts and figure hereafter, we introduce the following notations. 
LT90GTEQ85: $\quad$ Score is less than $90 \%$ \& greater than or equal to $85 \%$

LT45GTEQ40: $\quad$ Score is less than $45 \%$ \& greater than or equal to $40 \%$

AGRI: Agricultural Engineering

BLEX: Electronics Engineering

CIVL: Civil Engineering

COMP: Computer Engineering

ELEC: Electrical Engineering

GEOM: Geomatics Engineering

INDU: Industrial Engineering

MECH: Mechanical Engineering

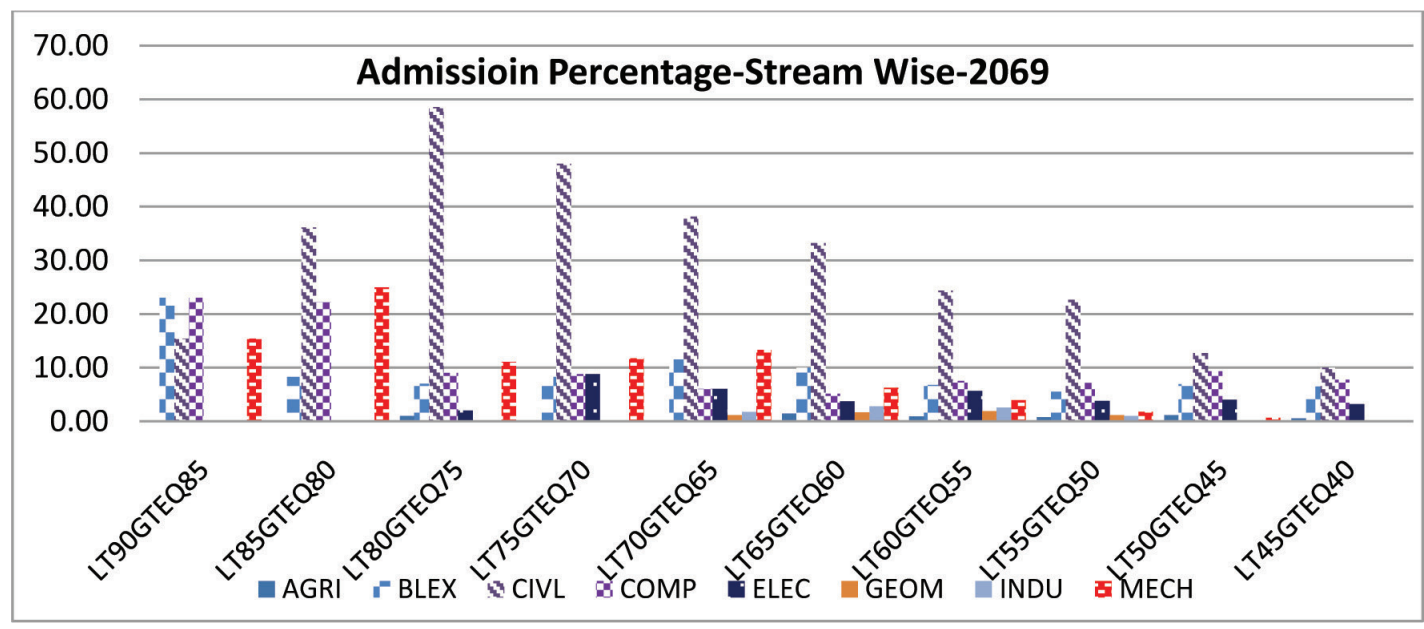

Fig. 2: Distribution of Admitted Students in the Year 2012AD

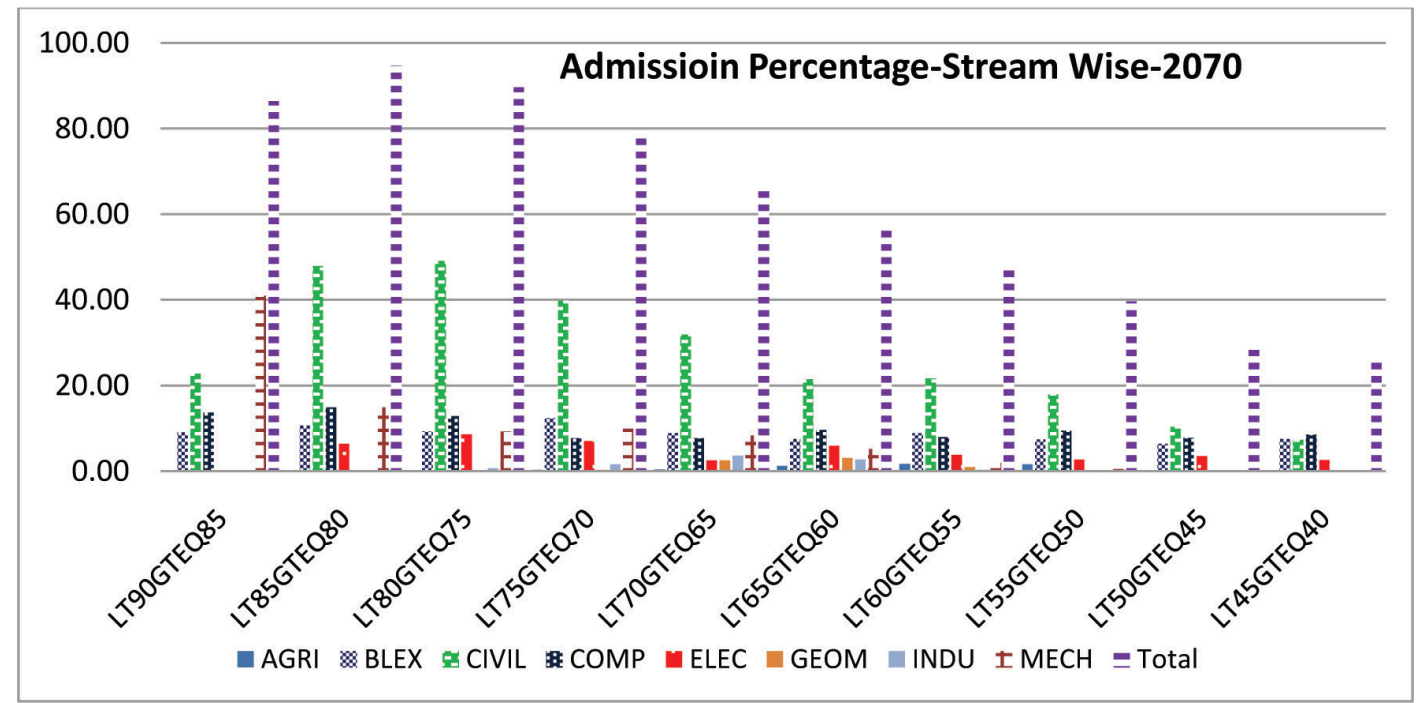

Fig. 3: Distribution of Admitted Students in the Year 2013AD 


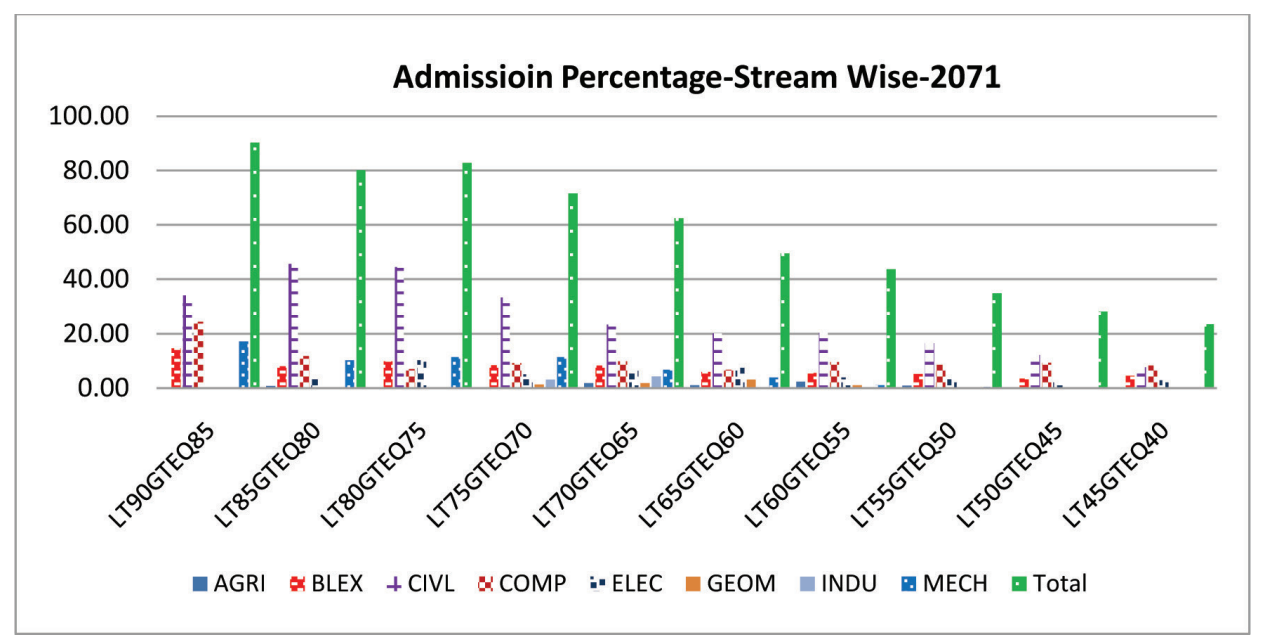

Fig. 4: Distribution of Admitted Students in the Year 2014 AD

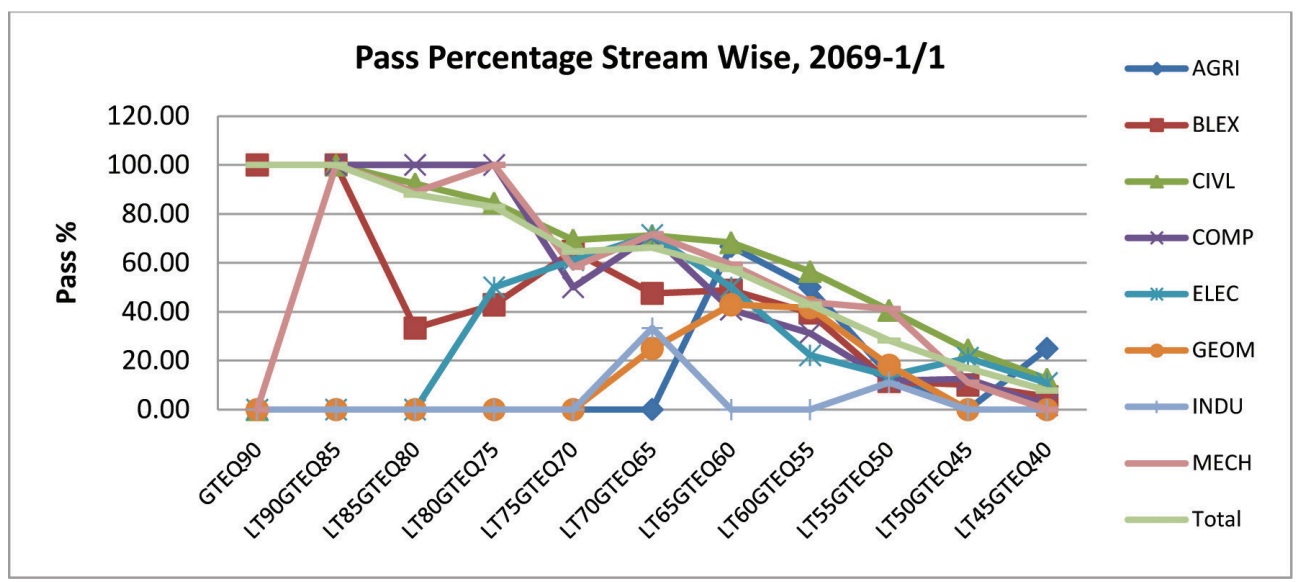

Fig. 5: Pass Rate Distribution of 069 (2012 AD) Batch Students in First Year First Semester

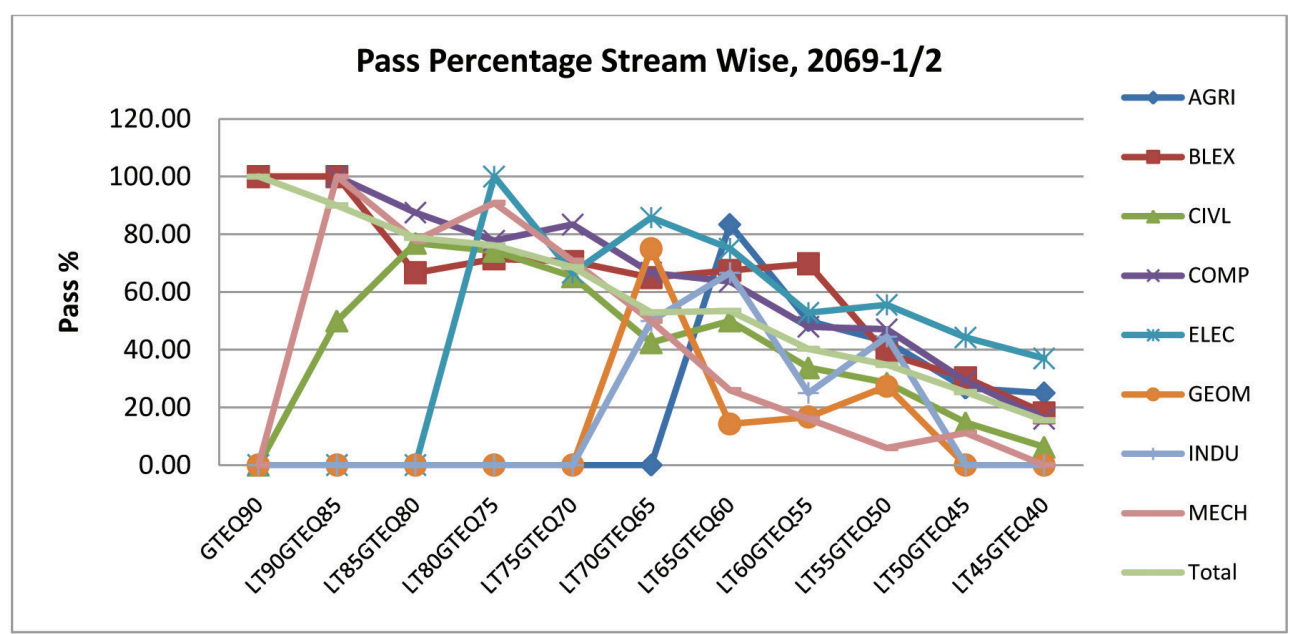

Fig. 6: Pass Rate Distribution of 069 (2012 AD) Batch Students in First Year Second Semester 


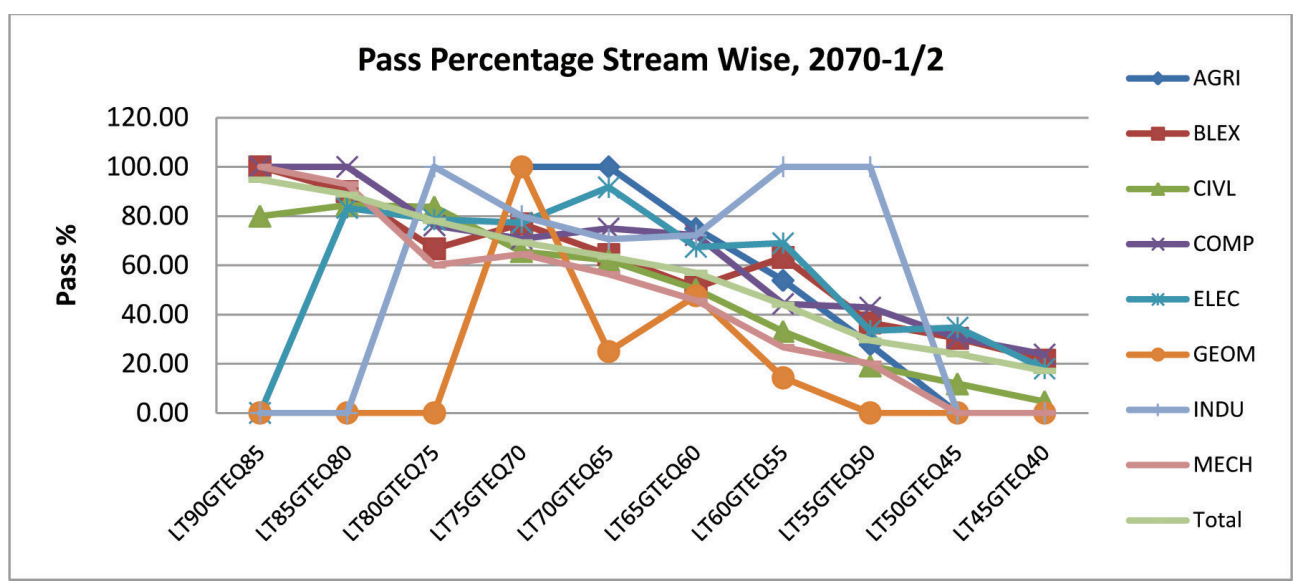

Fig. 7: Pass Rate Distribution of 070 (2013 AD) Batch Students in First Year Second Semester

Alternatively visualizing the chart of co-relation between admitted students number with pass students, Fig. 8 shows the ratio of admitted students count to number of passed students. This indicates that number of admitted students with low entrance rank is high while the number of passed students with this rank range is low. This clearly shows the inter-relationship between the quality intakes with quality results. We can see the same types of distribution for the other years like in 2013, 2014 and 2015.

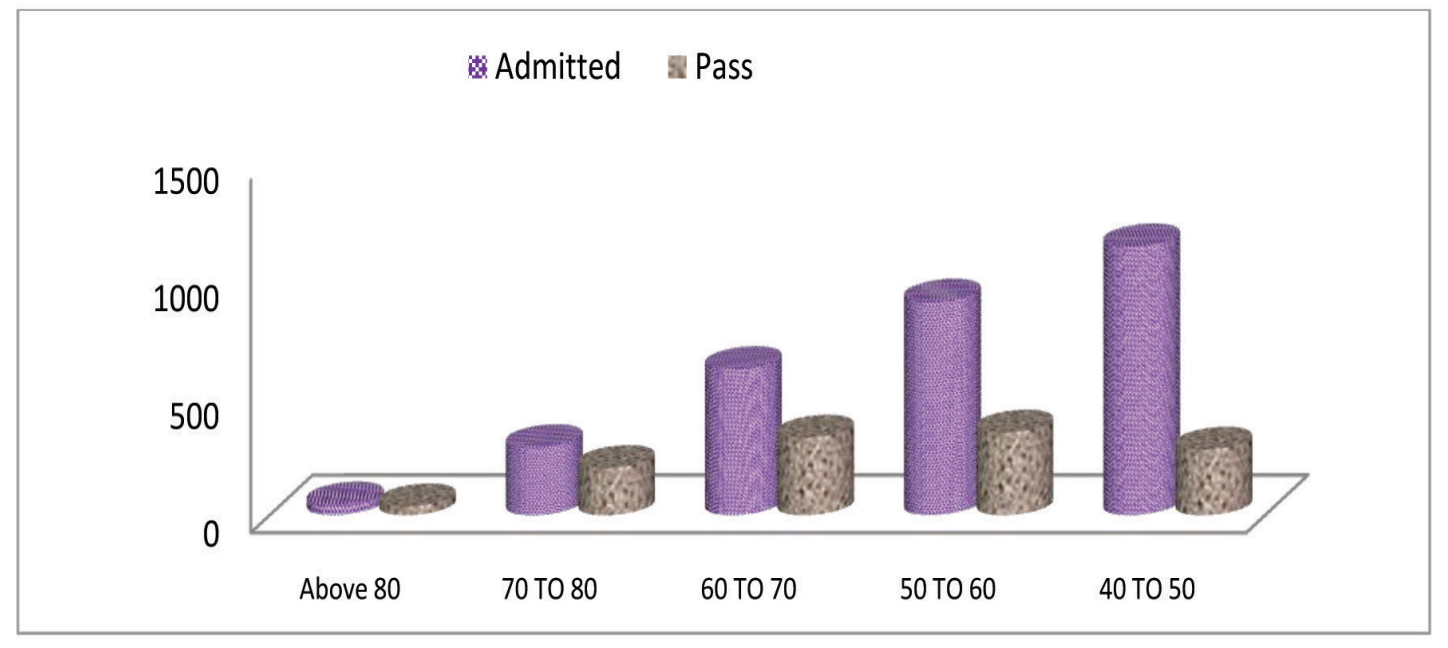

Fig. 8: Admitted Students and Their Pass Counts in the Year 2069 (2012 AD)

\section{Approaches for Admission Process Reform}

Three optional approaches proposed in [5,6] are 1) Central admission board receives online application for each campus/colleges and maintain the list, 2) Central admission board coordinates/ regulates for admission list generation, and 3) Central admission board receives application for all campus/college and admit the students. We reviewed the pros and cons of all three options considering the issues listed in section 2 where we need a solution for optimum admission process from the perspectives that are technically viable, administratively easy and hassle free activities 
for the students. Formation of central admission board at IOE, application to be received online and admission should be of computer based where any admission record shall be captured on the central database storage at real time, uniform admission schedule for all campus/colleges and no one student can admit at once to multiple campus/colleges are the common terms positively defined on all three options. First option just focus that IOE central admission board maintain the admission schedule for all campus/colleges and receive applications from individual candidates to each campus/college form the central admission portal while the applicant lists will be forwarded to campus/colleges just after completion of the application deadline. Then the campus/colleges prepare admission list and admit the candidates as per the approved applicant's list provided by central admission board. In the second options, IOE central admission board maintain the infrastructure to take separate application for each campus/colleges and generates admission list automatically where the campus/colleges simply enter into the central portal via secure channel and executes the software based online admission.

Although there are several factors that affect the students to attract admission to certain campus/ colleges, total study fee (cost of study), quality education and choice of programs are the major factors that attracts the students towards any campus/colleges. Reviewing the historical scenarios, IOE Pulchowk Campus is the first choice for any students to take admission then to other constituent campuses and finally to affiliated colleges. This kind of scenarios raised the concern that it is hard to implement uniformity in admission schedule. Students of middle range score always wait constituent campuses until the admission seats are almost packed then only think towards affiliated colleges. Options 1 and 2 simply strengthen the monitoring and regulation of campus/colleges but do not solve all the issues raised. Hence, the proposed third option is the completely automated centralized admission system where almost all the issues identified shall be avoided. The major activities and features of this approach are:

I. IOE central admission board opens admission application with a single admission schedule for all campus/colleges.

II. Candidates don't need to apply separately to each campus/colleges, rather they apply once from online with priority of programs listed for all campus/colleges. The choice of priority is left to the candidate him/herself on which campus/college he/she wants to admit. For example: the first priority shall be of college $\mathrm{X}$ and program $\mathrm{X} 1$ while second priority shall be on program $\mathrm{Y} 2$ of college $\mathrm{Y}$.

III. First admission list guarantees the candidate's admission. Based on the priority programs applied, name of one candidate will be published for admission at only one campus/college in one admission list. If his/her score is not sufficient on the first priority in college $\mathrm{X}$, it will be automatically transferred to second and other priority programs and name will be published in the admission list on the program where his/her score become sufficient.

IV. The admission process is fully secured and online based. Once the admission list is published, candidates perform admission online. IOE central admission board fixes the admission amount of each student for corresponding campus/colleges where candidates deposit the amount via bank and validate the voucher number before admission process starts.

V. Candidates shall be provisionally admitted via online. Corresponding campus/colleges finally approve their admission by entering into their login portal. The provisionally admitted students only for that campus/colleges will be listed in their portal where campus/college 
have to approve the final admission after verifying their necessary documents (certificates, citizenship). Students should have to immediately visit the campus/college where he/she provisionally admitted with necessary required documents for final admission guarantee.

VI. If candidate's score is not sufficient for any program of his/her choice with the priority applied in one admission list, his/her name shall be published on the subsequent admission list or candidates shall change or add the priority for further admission lists.

VII. IOE central admission board shall reopen application after running certain admission lists if seats are still available on some campus/colleges and the number of applicants are not sufficient for the upcoming further admission list.

VIII. Once the admission process is closed, campus/colleges identify the total number of their students admitted and request to IOE central admission board to transfer the admission guarantee amount (seed amount) to their bank accounts.

IX. Students in his/her study period shall be tracked by his unique admission ID which shall be allowed to access academic resources, view results and other linked information in the university Education Management Information System (EMIS) during his/her academic period.

\section{Technical Framework for Centralized Admission System}

The implementation of the fully automated centralized admission system is relatively complex, because the priority list will be quite large in number and the system should have the capability of shifting applicants from program of one college to another program of another college, various quota system at the constituent campus/colleges etc. Suppose there are N number of campus/ colleges $\left(X_{1}, X_{2}, X_{3} \ldots \ldots . X n\right)$ and each campus/college has $\mathrm{K}$ number of programs where $\mathrm{K}$ varies like $K_{1}, K_{2}, K_{3}$ per campus/college according to the approved programs. For example, College $X_{1}$ has $K_{1}$ number of programs, college $X_{2}$ has $K_{2}$ number of programs. Hence the total priority programs $(\mathrm{N})$ shall be

$$
N=\sum_{i=1}^{n} \sum_{j=1}^{l} X_{i} * K_{j}, \text { where } X_{i}=1 \text { for } i \leq n
$$

Currently IOE has 14 campus/colleges and in total 79 priority programs. It is required to generate 79 admission lists. The activities that shall be carried on fully automated centralized admission system discussed in section 4 is technically conceptualized with respect to network infrastructure, process and use-case diagram. The system is proposed to be online based either to be developed on open source framework like PHP or JAVA or on the .Net Framework like C\# .net. The network and server infrastructure for the secure online admission system is recommended with the requirements: i) IOE maintains the dedicated web and database server over the secure data center to be managed at its own premises while Every campus/colleges maintain and launch their own admission portal to provide detail information about their campus/colleges by virtual hosting form IOE data center, ii) The data center is to be connected with a dedicated $5 \mathrm{Mbps}$ fiber link for admission and web hosting server shall be accessed from anywhere. 


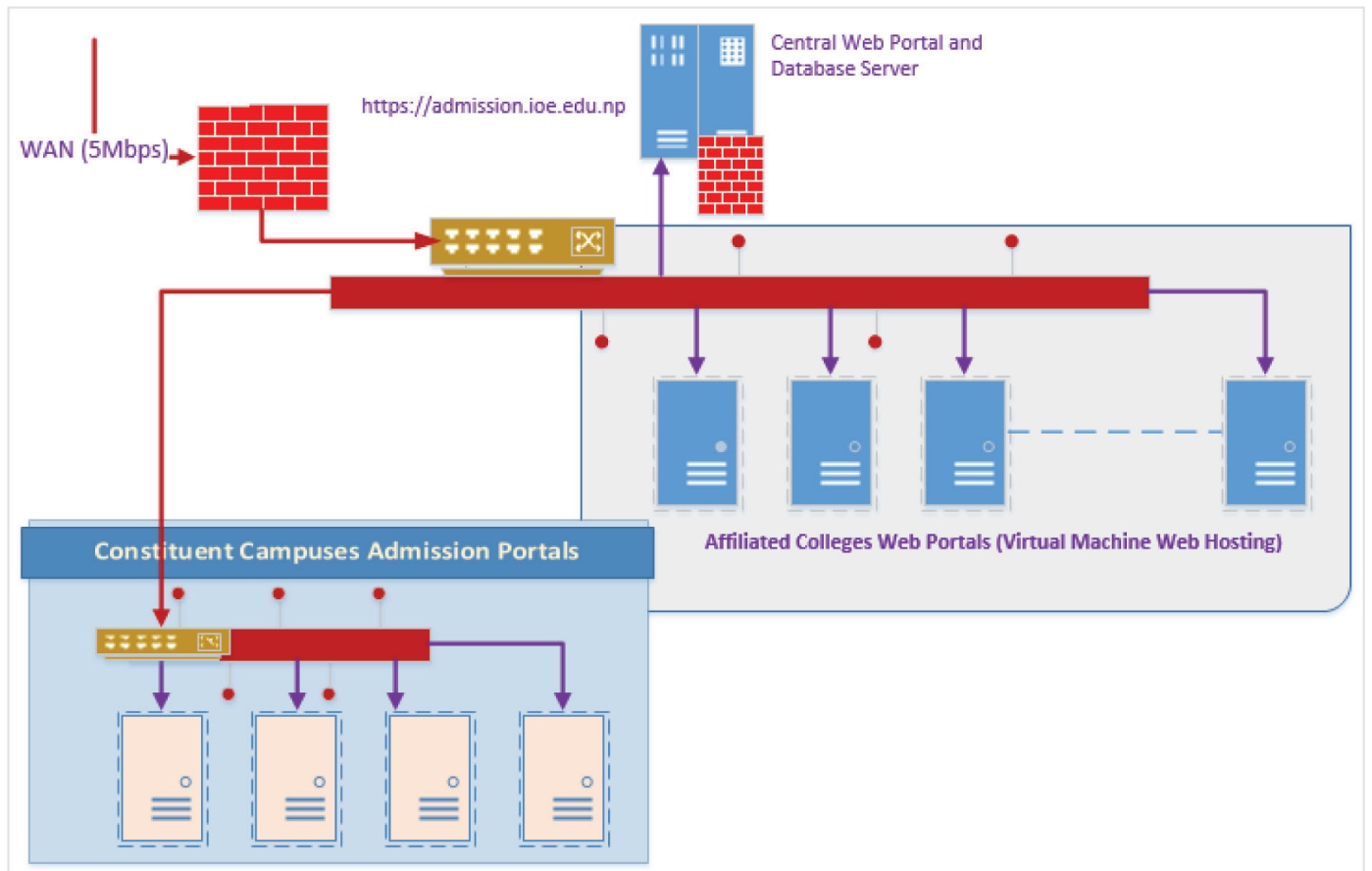

Fig. 9: Network \& Server Infrastructure Deployment Framework

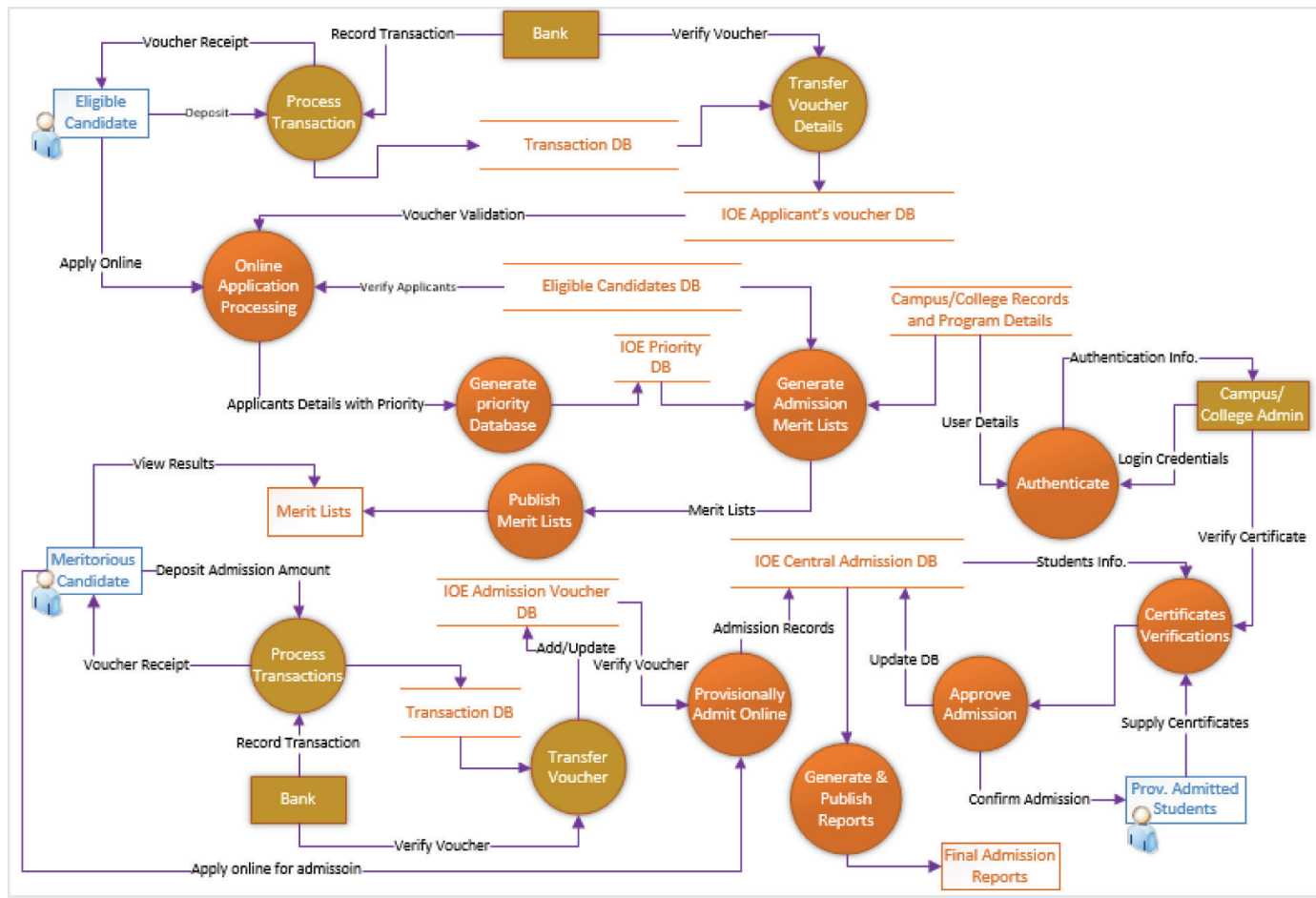

Fig. 10: Process Diagram of Proposed Centralized Admission System of IOE 


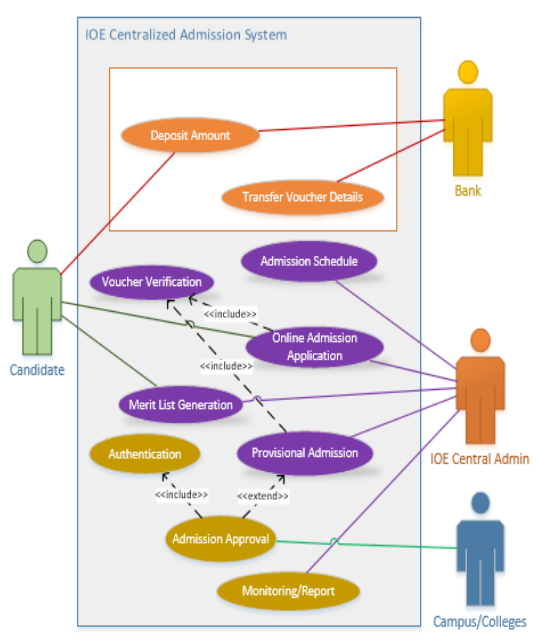

Fig. 11: Use-case diagram of centralized admission system

\section{Conclusion}

With this research, the existing admission process at IOE has been analyzed and its impact on the semester result has also been co-related. The most remarkable thing is that IOE is continuously improving its entrance system and admission process towards excellence. The low pass rate of low rank (entrance rank) students in the semester result verified the excellence of IOE entrance examination. The optional approaches proposed in the admission process reform are all the version of improvement while we analyzed the existing issues in IOE admission process. With these different existing issues and optimal minimization of those issues in the existing admission system, we reviewed the different optional approach and proposed the technical framework for fully automated online based centralized admission system for BE/BArch programs of IOE. Implementing this approach with proper security and governance are the recommendations for future research works.

Acknowledgement: This research study was supported by Institute of Engineering, Deans Office under its regular grants on "Steps towards Excellent Academic Environment at IOE". We are thankful to Prof. Ram Chandra Sapkota, Chair of Entrance Exam Board and Asst. Dean of Examination Control Division of IOE for his remarkable review and support to facilitate to make data available for this research.

\section{References}

[1] Bajracharya T (2015), Presentation Document: Brief Introduction of IOE

[2] IOE Entrance Exam Result Records since 2012

[3] IOE Entrance Information Booklet-2073, [Online], Available: http://entrance.ioe.edu.np

[4] IOE Semester Exam Result Records since 2012

[5] IOE Unified/Centralized Admission System Management Guideline-2016 (Draft).

[6] Nakarmi S et al. (2016), A study on the Probable Centralized/Unified Admission Process at IOE. Research Document for IOE.

[7] Pahari BR (2012), The Reform in Evaluation System as a Tool of Quality Improvement in Institute of Engineering, Journal of the Institute of Engineering, 10(1) : 1-13.

[8] Research Report, "Analysis of Higher and Engineering Education for Establishing Engineering Campus in Mid and Far Western Regions of Nepal", [Online], Available: www.ugcnepal.edu.np /reports/Education_Management_Information_System1.pdf 